\title{
Enhanced gastric nitric oxide synthase activity in duodenal ulcer patients
}

D Rachmilewitz, F Karmeli, R Eliakim, R Stalnikowicz, Z Ackerman, G Amir, J S Stamler

\begin{abstract}
Nitric oxide, the product of nitric oxide synthase in inflammatory cells, may have a role in tissue injury through its oxidative metabolism. Nitric oxide may have a role in the pathogenesis of duodenal ulcer and may be one of the mechanisms responsible for the association between gastric infection with Helicobacter pylori and peptic disease. In this study, calcium independent nitric oxide synthase activity was detected in human gastric mucosa suggesting expression of the inducible isoform. In 17 duodenal ulcer patients gastric antral and fundic nitric oxide synthase activity was found to be two and $1 \cdot 5$-fold respectively higher than its activity in the antrum and fundus of 14 normal subjects $(p<0.05)$. $H$ pylori was detected in the antrum of 15 of 17 duodenal ulcer patients and only in 7 of 14 of the control subjects. Antral nitric oxide synthase activity in $\boldsymbol{H}$ pylori positive duodenal ulcer patients was twofold higher than in $H$ pylori positive normal subjects $(\mathbf{p}<0.05)$. In duodenal ulcer patients antral and fundic nitric oxide synthase activity resumed normal values after induction of ulcer healing with ranitidine. Eradication of $\boldsymbol{H}$ pylori did not further affect gastric nitric oxide synthase activity. These findings suggest that in duodenal ulcer patients stimulated gastric mucosal nitric oxide synthase activity, though independent of the $H$ pylori state, may contribute to the pathogenesis of the disease.
\end{abstract}

(Gut 1994; 35: 1394-1397)

Pathology, Hadassah

University Hospital,

Mount Scopus,

Hebrew University -

Hadassah Medical

School, Jerusalem,

Israel

D Rachmilewitz

F Karmeli

R Eliakim

R Stalnikowicz

Z Ackerman

G Amir

Respiratory and Cardiovascular

Division, Brigham and

Women's Hospital, Boston,

Massachusetts, USA

J S Stamler

Correspondence to: Dr D Rachmilewitz, Department of Medicine, Hadassah University Hospital, Mount Scopus, Hospital, Mount Scopus, PO Box 24035, Jerusalem

Accepted for publication 19 January 1994 use of non-steroidal anti-inflammatory drugs and abnormal hypersecretory states. Persistent infection with $H$ pylori is associated with the recurrence of duodenal ulcer, which is significantly decreased by its eradication. ${ }^{3}$ The mechanism, however, whereby $H$ pylori infection of the gastric mucosa is responsible for duodenal ulceration is unclear. Enhanced gastric generation of nitric oxide by activated macrophages and inflammatory neutrophils present in the inflamed mucosa may, by its direct toxic effects, contribute to the pathogenesis of peptic ulcer disease. The aim of this study was to determine and compare gastric nitric oxide synthase activity in normal subjects and duodenal ulcer patients before and after induction of ulcer healing and eradication of $H$ pylori.

\section{Methods}

Endoscopic biopsy specimens were obtained from the stomach antrum and fundus of 17 patients with active duodenal ulcer, $M: F$ 10:7, mean age 30.4 years; and from 14 normal controls $M: F$ 7:7, mean age 32 years. In nine of the duodenal ulcer patients biopsy specimens were also obtained after four weeks of treatment with ranitidine $300 \mathrm{mg}$ at bedtime, resulting in ulcer healing and also after 14 additional days of treatment with metronidazole $500 \mathrm{mg}$ thrice daily and amoxicillin $750 \mathrm{mg}$ thrice daily. None of the duodenal ulcer patients received non-steroidal antiinflammatory drugs (NSAIDs) or any other treatment at least one month before the diagnosis was established endoscopically. All the normal controls had endoscopy for nonulcer dyspepsia and in none of them was an abnormality found in the upper gastrointestinal tract or elsewhere.

In all subjects endoscopy was performed after 10 hours fast with the Olympus videoscope and biopsy specimens were obtained with the Olympus $12 \mathrm{BK}$ biopsy forceps. In each subject four to five specimens were obtained from the stomach antrum and four to five specimens from the fundus. From each region one specimen was used for the rapid urease test and one was fixed in $8 \%$ phosphate buffered formalin $\mathrm{pH} 7 \cdot 4$ and embedded in paraffin wax. Sections were stained with haematoxylin and eosin or with Giemsa stain. These sections were blindly evaluated for the presence or absence of $H$ pylori. Subjects were considered $H$ pylori negative if the organism was not identified in the stained histological sections and the rapid urease test was negative. Biopsy specimens were graded for the presence or absence of chronic and acute inflammation using an index of gastritis developed previously. ${ }^{4}$ For chronic inflammation the following criteria were used: $0=$ normal $(\leqslant 5$ mononuclear cells per high power field); $1=$ mild (6-20 mononuclear cells per high power field with inflammation affecting only 
TABLE I Gastric nitric oxide synthase activity (\% of basal activity)

\begin{tabular}{|c|c|c|c|c|}
\hline & \multicolumn{2}{|c|}{ Normal subjects } & \multicolumn{2}{|c|}{ Duodenal ulcer patients } \\
\hline & Antrum & Fundus & Antrum & Fundus \\
\hline $\begin{array}{l}\text { NADPH } \\
\text { EGTA } \\
\text { L-NAME }(10 \mathrm{mM}) \\
\text { L-NAME }(100 \mathrm{mM})\end{array}$ & $\begin{array}{l}40(8)^{\star} \\
86(24) \\
63(19) \\
39(16)^{\star}\end{array}$ & $\begin{array}{l}55(11)^{\star} \\
83(18) \\
64(19) \\
65(14)^{\star}\end{array}$ & $\begin{array}{l}78(6)^{\star} \\
70(15) \\
45(20)^{\star}\end{array}$ & $\begin{array}{l}58(12)^{\star} \\
87(9) \\
67(8)^{\star}\end{array}$ \\
\hline
\end{tabular}

Endoscopic biopsy specimens were obtained from the stomach antrum and fundus of duodenal ulcer patients and normal controls. Nitric oxide synthase activity was determined in the presence or absence of $\mathrm{N}^{\mathrm{G}}$-monomethyl-L-arginine (L-NAME)EGTA $(1 \mathrm{mM})$ or NADPH $(100 \mu \mathrm{M})$ as described in methods. In normal subjects basal antral and fundic nitric oxide synthase activity was $3.5(0.6)$ and $4.4(0.6) \mathrm{nmol} / \mathrm{g} / \mathrm{min}$ and in duodenal ulcer patients, $6.6(1.0)$ and $6.7(0.7)$ $\mathrm{nmol} / \mathrm{g} / \mathrm{min}$, respectively, and was regarded as $100 \%$. Results are mean (SEM) of experiments performed with tissue obtained from five to eight subjects in each group. ${ }^{\star S i g n i f i c a n t l y ~ d i f f e r e n t ~}$ from basal activity, $\mathrm{p}<0.05$ ( $t$ test for paired data).

the superficial epithelium); $2=$ moderate (21-40 mononuclear cells per high power field with deep inflammation affecting the glands); and $3=$ severe $(>40$ mononuclear cells per high power field). Acute inflammation was graded in a similar fashion, grades severity based on the number of polymorphonuclear cells. Two to three specimens obtained from each region were washed in ice cold $0.15 \mathrm{M}$ $\mathrm{NaCl}$, weighed (average weight $9 \mathrm{mg}$ ), and processed for determination of nitric oxide synthase activity. The study was approved by the institutional Helsinki Committee.

Nitric oxide synthase activity was monitored by the conversion of $\left[{ }^{3} \mathrm{H}\right]-\mathrm{L}$-arginine to citrulline according to Bush et al. ${ }^{5}$ Biopsy specimens, 10-15 mg wet weight, were homogenised for 30 seconds at $4^{\circ} \mathrm{C}$ with a Polytron (Kinematica $\mathrm{GmbH}$, KrienzLuzerne, Switzerland) in $0.3 \mathrm{ml}$ of ice cold 50 $\mathrm{mM}$ TRIS $\mathrm{HCl}, \mathrm{pH} 7 \cdot 4$, containing $0 \cdot 1 \mathrm{mM}$ EDTA, $0.1 \mathrm{mM}$ EGTA, $0.5 \mathrm{mM}$ dithiothreitol, $1 \mathrm{mM}$ phenylmethylsulphonyl fluoride. Homogenates were centrifuged at $20000 \times g$ for 60 minutes at $4^{\circ} \mathrm{C}$ and the supernatant was used as the source of nitric oxide synthase. Enzymatic reactions were conducted at $37^{\circ} \mathrm{C}$ in $50 \mathrm{mM}$ TRIS $\mathrm{HCl}, \mathrm{pH} 7 \cdot 4$, containing $100 \mu \mathrm{M}$ L-arginine, $100 \mu \mathrm{M}$ NADPH, $2 \mathrm{mM} \mathrm{CaCl}, 0 \cdot 20-0 \cdot 40 \mathrm{mg}$ supernatant proteins, other test agents as indicated, and about $200000 \mathrm{dpm}$ of L-[2,3,4,5-3 H]arginine $\mathrm{HCl}(77 \mathrm{Ci} / \mathrm{mmol}$ ) (Amersham) to a

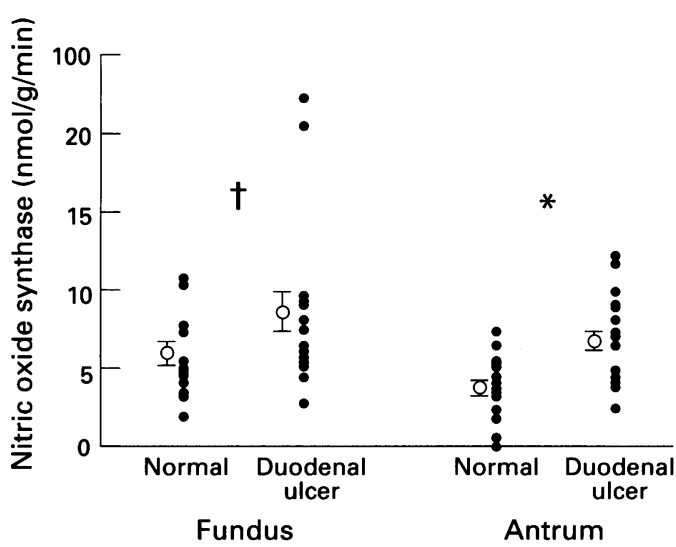

Figure 1: Gastric nitric oxide synthase activity in duodenal ulcer patients and normal subjects. Gastric antral and fundic nitric oxide synthase activity was determined in endoscopic biopsy specimens obtained from 17 duodenal ulcer patients and from 14 normal subjects. ${ }^{*}$ Significantly different from normal subjects $p<0.05$ ( $\mathrm{t}$ test for unpaired data and Mann-Whitney test); $+p<0.05$ (Mann-Whitney test). final volume of $100 \mu$ l. Enzymatic reactions were terminated by addition of $2.0 \mathrm{ml}$ of ice cold 'stop buffer': $20 \mathrm{mM}$ sodium acetate, pH 5.5, 1 mM L-citrulline, 2 mM EDTA, and $0 \cdot 2 \mathrm{mM}$ EGTA.

Citrulline was determined by applying the samples $(2.0 \mathrm{ml})$, prepared as described above, to columns ( $1 \mathrm{~cm}$ diameter) containing $1.0 \mathrm{ml}$ of Dowex AG50W-X8, Na form, that had been pre-equilibrated with stop buffer. Columns were eluted with $6 \times 1.0 \mathrm{ml}$ of water, collected into scintillation vials. Aquasol-2 $(10 \mathrm{ml})$ was added to each vial and samples were counted in a Beckman LS 3801 liquid scintillation spectrometer. Citrulline was recovered in the first $4.0 \mathrm{ml}$ of the Dowex column eluate to the extent of 96 (2)\%. Enzyme activities performed in duplicates showed variability of $2 \%$.

Data are expressed as mean (SEM). Statistical analysis for significant differences was performed according to the Student's $t$ test for paired and unpaired data and the nonparametric Mann-Whitney U test.

\section{Results}

Nitric oxide synthase activity detected in the stomach antrum and fundus of duodenal ulcer patients and normal controls was significantly inhibited by the deletion of NADPH and by the arginine analogue, $\mathrm{N}^{\mathrm{G}}$-monomethyl-Larginine. Sequestration of calcium with EGTA did not result in a significant decrease in antral or fundic nitric oxide synthase activity both in duodenal ulcer patients and in normal subjects (Table I), suggesting expression of the inducible isoform. ${ }^{1}$ Nitric oxide synthase activity in the antrum and fundus of patients with active duodenal ulcer was two and 1.5 -fold higher, respectively, $(p<0.05)$ than in the antrum and fundus of normal controls (Fig 1). In 15 of 17 duodenal ulcer patients $H$ pylori was identified in the antrum and fundus both histologically, and by the rapid urease test. In contrast, $H$ pylori was identified in the antrum and fundus of only seven of 14 controls.

Antral nitric oxide synthase activity in $H$ pylori positive duodenal ulcer patients was twofold higher than antral nitric oxide synthase activity in $H$ pylori positive normal subjects. Fundic nitric oxide synthase activity in duodenal ulcer patients with $H$ pylor $i$ was higher than in normal subjects with $H$ pylori but the difference was not significantly different (Table II). In nine duodenal ulcer patients a significant decrease in antral and fundic nitric oxide synthase activity was seen once the ulcer healed after four weeks of treatment with ranitidine even when $H$ pylori was still present in six of them. In these subjects eradication of $H$ pylori with 14 additional days of antibiotic treatment did not further decrease antral or fundic nitric oxide synthase activity (Fig 2).

Mean (SEM) antral chronic inflammation scores were similar in $H$ pylori positive duodenal ulcer patients and normal subjects: $2 \cdot 4$ $(0.3)$ and $2.5(0.3)$ respectively. Acute inflammation scores were also similar in both groups: 
TABLE II Gastric nitric oxide synthase activity in duodenal ulcer patients and normal subjects

\begin{tabular}{|c|c|c|c|c|c|c|}
\hline & \multicolumn{3}{|c|}{ Normal subjects } & \multicolumn{3}{|c|}{ Duodenal ulcer patients } \\
\hline & No & Antrum & Fundus & No & Antrum & Fundus \\
\hline $\begin{array}{l}\text { All subjects } \\
\text { Helicobacter pylori }(+) \\
\text { Helicobacter pylori }(-)\end{array}$ & $\begin{array}{r}14 \\
7 \\
7\end{array}$ & $\begin{array}{l}3 \cdot 7(0.5) \\
3 \cdot 5(0 \cdot 8) \\
3.8(0 \cdot 7)\end{array}$ & $\begin{array}{l}5 \cdot 9(0 \cdot 7) \\
6 \cdot 4(1 \cdot 1) \\
5 \cdot 4(1 \cdot 0)\end{array}$ & $\begin{array}{r}17 \\
15 \\
2\end{array}$ & $\begin{array}{l}6 \cdot 7(0 \cdot 6)^{\star} \\
7 \cdot 0(0 \cdot 7)^{\star} \\
4 \cdot 8\end{array}$ & $\begin{array}{r}8 \cdot 5(1 \cdot 2) \dagger \\
7 \cdot 9(1 \cdot 0) \\
13 \cdot 3\end{array}$ \\
\hline
\end{tabular}

Endoscopic biopsy specimens were obtained from the stomach antrum and fundus of duodenal ulcer patients and normal controls. The presence or absence of $H$ pylori was assessed both by the rapid urease test and on histological sections and nitric oxide synthase activity (nmol/g/min) was rapid urease test and on histological sections and nitric oxide synthase activity (nmol/g/min) was
determined as described in methods. Results are mean (SEM); ${ }^{\circ}$ Significantly different from determined as described in methods. Results are mean (SEM); ${ }^{\star}$ Significantly different from
normal subjects, $\mathrm{p}<0.05$ ( $t$ test for unpaired data and Mann-Whitney test); + Significantly different from normal subjects, $\mathrm{p}<0.05$ (Mann-Whitney test).
(Mann-
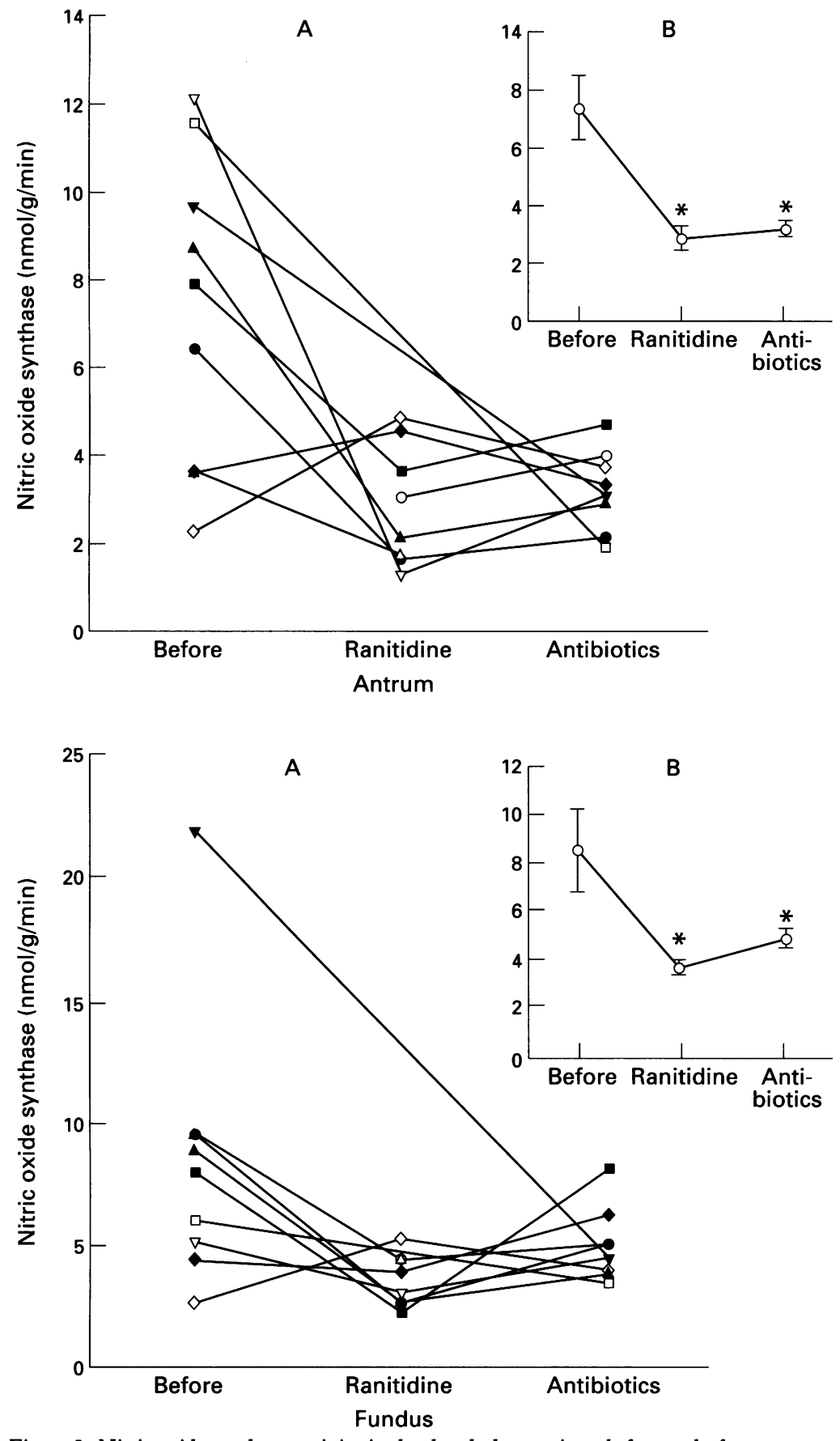

Figure 2: Nitric oxide synthase activity in duodenal ulcer patients before and after treatment. Endoscopic biopsy specimens were obtained from the stomach antrum and fundus of nine duodenal ulcer patients before and after four weeks of treatment with ranitidine $300 \mathrm{mg}$ at bedtime when the ulcer healed and after an additional 14 days of treatment with metronidazole $500 \mathrm{mg}$ thrice daily and amoxicillin $750 \mathrm{mg}$ thrice daily. The presence or absence of $\mathrm{H}$ pylori was assessed on mucosal biopsy specimens, histologically, and by the rapid urease test, and nitric oxide synthase activity (nmol/g/min) was determined as described in methods. $(A)$ Points joined by lines represent determinations performed with specimens obtained from the same patient; $(B)$ results are mean (SEM). ${ }^{\star}$ Significantly different from before treatment, $p<0 \cdot 01$.
$1 \cdot 4(0 \cdot 2)$ and $1 \cdot 2(0 \cdot 4)$ respectively. After treatment with ranitidine, antral acute and chronic inflammation scores in duodenal ulcer patients were $0.6(0.4)(n=5)$ and $2.4(0.2)(n=5)$, respectively. In these patients antral acute and chronic inflammation scores after eradication of $H$ pylori with antibiotics were $0.5(0.3)$ and $2 \cdot 0(0 \cdot 2)$, respectively. The decrease did not reach statistical significance.

\section{Discussion}

An inducible nitric oxide synthase activity, the enzyme subtype present in inflammatory neutrophils and macrophages, was found to be expressed in gastric mucosa of normal subjects, as well as duodenal ulcer patients. The enhanced inducible nitric oxide synthase activity in gastric mucosa of duodenal ulcer patients is probably derived from inflammatory neutrophils and macrophages. Endothelial cells fibroblasts and mast cells may also contribute to nitric oxide generation but in these cells nitric oxide synthase is constitutive and calcium dependent. In duodenal ulcer patients there is a high incidence of gastric infection with $H$ pylori inducing gastritis, which is characterised by abundance of activated inflammatory cells. ${ }^{6}$ Eighty eight per cent of duodenal ulcer patients, compared with $50 \%$ of the normal controls included in this study, were found to be infected with $H$ pylori. Antral nitric oxide synthase activity in duodenal ulcer patients with $H$ pylori was significantly higher than in uninfected patients or infected normal subjects. It is therefore possible that the enhanced antral nitric oxide synthase activity in duodenal ulcer patients is related to their infection with $H$ pylori and is derived from the abundant macrophages and inflammatory neutrophils in the inflamed mucosa.

The mechanisms whereby $H$ pylori contribute to ulcer formation are obscure. Enhanced nitric oxide generation by stimulated nitric oxide synthase activity may contribute to the pathogenesis of peptic ulceration. Nitric oxide may induce tissue injury because of the simultaneous generation by macrophages of superoxide and nitric oxide yielding peroxynitrite. ${ }^{2}$ Peroxynitrite decompose to $\mathrm{OH}$ and $\mathrm{NO}_{2}$, which oxidises sulphydryl groups and react with metal ions. ${ }^{7}$ Exposure of duodenal mucosa to peroxynitrite originating in the gastric antral mucosa may induce or amplify tissue injury. We have shown that exposure of colonic mucosa to peroxynitrite results in significant tissue injury. ${ }^{8}$ Nitric oxide, identified as a neurotransmitter of nonadrenergic non-cholinergic neurons in the gut, is a potent inhibitor of gastrointestinal smooth muscle contraction. ${ }^{9}$ Stimulated nitric oxide generation, as herewith shown, may therefore also delay proximal duodenal contractions, thus increasing the exposure of duodenal mucosa to gastric acidity. It is unlikely that enhanced nitric oxide generation amplifies tissue damage by stimulation of gastric acid secretion as the nitric oxide pathway was shown not to participate in the vagal regulation of gastric acid secretion. ${ }^{10}$ Likewise, L-NAME 
was reported to have no effect on pentagastrin stimulated gastric acid secretion. ${ }^{10}$ Enhanced nitric oxide generation by inflamed gastric mucosa of $H$ pylori infected subjects may also be beneficial. Nitric oxide was shown to mediate gastric mucosal blood flow and to contribute to mucosal vasodilation associated with stimulation of gastric acid secretion, ${ }^{11}$ thus contributing to maintenance of gastric integrity. Inhibitors of nitric oxide synthesis were shown to aggravate aspirin induced gastric damage. ${ }^{12}$ Enhanced nitric oxide generation may also be beneficial and protective in view of the bactericidal effects of peroxynitrite. ${ }^{13}$ One may further speculate that duodenal ulcers result from overproduction of nitric oxide in an attempt to control infection in the antrum.

In duodenal ulcer patients the enhanced gastric nitric oxide synthase activity resumed normal values after induction of ulcer healing with ranitidine but was not further decreased after antibiotic treatment, resulting in the successful eradication of $H$ pylori. The significant decrease in gastric nitric oxide synthase activity after treatment with an anti-secretory drug independent of cotreatment with antibiotics suggests the important contribution of gastric acidity to the perpetuation of mucosal inflammation. The acidic environment may contribute to nitric oxide mediated toxicity in several ways. Firstly, it is mandatory for protonation of peroxynitrite before its decay to the potent biological oxidants $\mathrm{OH}$ and $\mathrm{NO}_{2}$, which exist only in acidic $\mathrm{pH}$. Secondly, nitrosation of proteins and nucleic acids is facilitated by acidic conditions leading to impaired protein function and mutations in DNA. We have previously reported in duodenal ulcer patients increased mucosal concentrations of the proinflammatory mediators leukotrine $\mathrm{B}_{4}$, leukotriene $\mathrm{C}_{4}$, and platelet activating factor, which resume normal concentrations after induction of ulcer healing with anti-secretory drugs. ${ }^{14}$

Enhanced gastric nitric oxide synthase activity in duodenal ulcer patients may contribute to the pathogenesis of peptic ulcer disease. Stimulated nitric oxide generation by inflamed gastric mucosa may be one of the possible, though not the sole mechanism to explain a link between $H$ pylori infection and peptic duodenal ulcer.

Dr J S Stamler is a pew scholar in the Biomedical Services and a recipient of the Clinical Investigator Award from the NIH (K08HL02582)

1 Nathan C. Nitric oxide as a secretory product of mammalian cells. FASEB 7 1992; 6: $3051-64$

2 Beckman JS, Beckman TW, Chen J, Marshall PA, Freeman BA. Apparent hydroxyl radical production by peroxynitrite: implications for endothelial injury from nitric oxide and superoxide. Proc Natl Acad Sci USA 1990; 87: 1620-4.

3 Hentschel E, Brandstatter G, Dragosics B, Hirschl AM, Nemee $\mathrm{H}$, Schutze $\mathrm{K}$, et al. Effect of ranitidine and amoxicillin plus metronidazole on the eradication of Helicobacter pylori and the recurrence of duodenal ulcer. H Engl f Med 1993; 328: 308-12.

4 Talley NJ, Cameron AJ, Shorter RG, Zinsmeister AR, Phillips SF. Campylobacter pylori and Barrett's Phillips SF. Campylobacter pylori and

5 Bush PA, Gonzalez NE, Griscavage JM, Ignarro LJ. Nitric oxide synthase from cerebellum catalyzes the formation of equimolar quantities of nitric oxide and citrulline from L-arginine. Biochem Biophys Res Commun 1992; 185: 960-6.

6 Graham DY. Helicobacter pylori: its epidemiology and its role in duodenal ulcer disease. $\mathcal{F}$ Gastroenterol Hepatol 1991; 5: 105-13.

7 Radi R, Beckman JS, Bush KM, Freeman BA. Peroxynitrite-induced membrane lipid peroxidation: the cytotoxic potential of superoxide and nitric oxide. cytotoxic potential of superoxide and

8 Rachmilewitz D, Stamler JS, Karmeli F, Mullins ME, Singel DJ, Loscalzo J, et al. Peroxynitrite induced experimental colitis - a new model indicating possible contribution of the NO radical to the pathogenesis of colonic inflammation. Gastroenterology 1993; 105: 1681-8.

9 Stark ME, Szurszewski JH. Role of nitric oxide in gastrointestinal and hepatic function and disease. Gastroenterology 1992; 103: 1928-49.

10 Tanaka T, Guth P, Tache Y. Role of nitric oxide in gastric hyperemia induced by central vagal stimulation. Am 7 Physiol 1993; 264: G280-4.

11 Pique JM, Esplugues JV, Whittle BJR. Endogenous nitric oxide as a mediator of gastric mucosal vasodilation during acid secretion. Gastroenterology 1992;102: 168-74.

12 Stroff T, Lambrecht N, Peskar BM. Inhibitors of nitric oxide biosynthesis aggravate rat gastric mucosal damage after topical but not parenteral aspirin. Gastroenterology 1993; 104: A200.

13 Zhu L, Gunn C, Beckman JS. Bactericidal activity of peroxynitrite. Arch Biochem Biophys 1992; 298: 452-7.

4 Lysy J, Karmeli F, Wengrower D, Rachmilewitz D. Effect of duodenal ulcer healing induced by omeprazole and ranitidine on the generation of gastroduodenal eicosanoids, platelet activating factor, pepsinogen A and gastrin in duodenal ulcer patients. Scand 7 Gastroenterol 1992; 27: 13-20. 